Article

\title{
Exploring Military Artefacts in Early Childhood Education: Conflicting Perspectives on Cultural Sustainability, Belonging and Protection
}

\author{
Åsta Birkeland *(1) and Liv Torunn Grindheim (1)
}

check for

updates

Citation: Birkeland, Å.; Grindheim, L.T. Exploring Military Artefacts in Early Childhood Education:

Conflicting Perspectives on Cultural Sustainability, Belonging and Protection. Sustainability 2021, 13, 2587. https://doi.org/10.3390/ su13052587

Academic Editors: Cecilia Ruiz Esteban and Veronica Bergan

Received: 15 December 2020

Accepted: 23 February 2021

Published: 28 February 2021

Publisher's Note: MDPI stays neutral with regard to jurisdictional claims in published maps and institutional affiliations.

Copyright: (c) 2021 by the authors. Licensee MDPI, Basel, Switzerland. This article is an open access article distributed under the terms and conditions of the Creative Commons Attribution (CC BY) license (https:/ / creativecommons.org/licenses/by/ $4.0 /)$.
KINDknow-Kindergarten Knowledge Centre for Systemic Research on Diversity and Sustainable Futures, Faculty of Teacher Education, Arts and Sports, Western Norway University of Applied Sciences, 5063 Bergen, Norway; ltg@hvl.no

* Correspondence: abi@hvl.no; Tel.: +47-5558-5987

\begin{abstract}
Social and cultural sustainability is outlined as creating surroundings that include and stimulate positive interactions, such as promoting a sense of community and a feeling of belonging to a community, by being safe and attached to the local area. Artefacts chosen in early childhood education (ECE) institutions are integrated parts of the culture in which the ECE institutions are embedded; artefacts, thus, are understood as serving belonging and cultural sustainability. The study examined what insight into cultural sustainability could be surfaced in conflicting perspectives about military artefacts in ECE. Focus group interviews were conducted with Chinese and Norwegian graduate students and ECE researchers, during which photographs of a Chinese kindergarten where military artefacts and toys were highly represented. Conflicting perspectives on military artefacts among the participant surfaced how belonging are closely intertwined with protection and where to belong: locally, nationally or internationally. The skeptical approach to military artefacts is challenged by awareness of different ways to promote national pride and entanglement among generations. The findings indicate a need for more research on conditions for belonging and the normative complexities of artefacts in cultural sustainability.
\end{abstract}

Keywords: early childhood education; cultural sustainability; military artefacts

\section{Introduction}

Education, including early childhood education (ECE), is put forward as important when aiming at more sustainable living [1-4]. Although sustainability requires multifactorial, intra-disciplinary approaches that include ecological, economic, social/cultural and political dimensions [5-8], we focus on social and cultural sustainability. We aim to contribute to broadening sustainable thinking and practices, by investigating a dimension of sustainability that is often left in the shadows [9]. Furthermore, we intentionally investigate conflicting perspectives towards cultural sustainability to forward normative complexities.

Social and cultural sustainability points to development that ensures safety, social rights and good living conditions for all [9], as "a life-promoting state within communities and a process within communities that can achieve this condition" [10] (p. 12). Mannion and Adey [11] and Grindheim et al. [7] see social and cultural sustainability in the context of ECE as creating surroundings that include and stimulate positive interactions, such as promoting a sense of community and a feeling of belonging to the community in which we live, by being safe and attached to the local area. A contradictory and important aspect of cultural sustainability emerges when facing challenges such as migration [9], pollution [12] or wars. In these perspectives, local involvement and belonging may not be enough to achieve sustainability. Therefore, local, national and global belonging are asked for. The issue of global coexistence calls for perspectives on belonging beyond the local or national state. 
We assume that the perspectives on belonging and proper artefacts may be conflicting when discussing this issue from the position of Chinese or Norwegian ECE; the People's Republic of China and Norway have different histories, cultural traditions and political systems. In addition, the nations are very different in size and population, representing one of the largest populations and one of the smallest populations globally. China comprises almost 1.4 billion people including 56 minority groups with different languages and traditions; Norway has 5.3 million people and has the last 40 years developed from a mainly homogenous population, with the exception of a minor indigenous population, to become more heterogeneous population due to labor and refugee immigration. As a consequence, the ECE in the two countries face different challenges and conditions in education for cultural sustainability. However, the question of children's belonging to family, kindergarten, local community, society and nation is addressed in the Chinese ECE Guidelines [13] and the Norwegian ECE Framework Plan [14].

With support from UNICEF, the Ministry of Education of China completed in 2012 the Early Learning and Development Guidelines (hereinafter referred to as the Guidelines) for children aged 3-6 years [13]. The Guidelines are quite specific and articulates expectations for children's learning and development in five different developmental areas. One of the learning areas is entitled Social Development and comprises four different benchmarks, to establish initial sense of belonging is but one. This benchmark highlights outcomes such as to know their nationality with many different ethnic groups and to know some significant achievements of the nation, to show love for their motherland and to feel proud of being Chinese.

The Norwegian Framework Plan for Kindergartens-Contents and Tasks [14] is a national framework for children aged 1-6 years. The Framework Plan addresses seven different learning areas where one is entitled Local Community and Society. Sense of belonging is strongly connected to the local community. The Framework plan highlights that children are supposed to learn about local history, places, persons and traditions in order to create a sense of belonging. Nation and national pride is not mentioned. However, the content shall enable children to participate in society on equal terms and learn about national minorities.

Although both the Chinese Guidelines and the Norwegian Framework plan forward belonging, we see that the cultural context where the children are supposed to belong, differs a lot. The local, institutional and cultural context are central to what is seen as important and what to emphasis when facilitating children cultural formation. A crucial aspect of cultural formation and belonging is available artefacts [15,16]. A controversial type of artefact is military artefacts $[17,18]$. Artefacts chosen in ECE institutions are integrated parts of the culture where the ECE institutions are embedded; artefacts, thus, are understood as serving belonging and cultural sustainability. Therefore, we suggest that artefacts are culturally sensitive and by investigating conflicting arguments for their (non-) appearance, we can glimpse some of the values and understandings of cultural sustainability and conditions for belonging, which we take for granted. This article is therefore guided by the following question: What insight into cultural sustainability can be surfaced in conflicting perspectives on military artefacts in ECE? This question is investigated from analysis of focus group interviews with Chinese and Norwegian graduate students and ECE researchers. The interviews aimed to seek conflicting perspectives from how Norwegian and Chinese early childhood education graduate students and researchers perceive photographs depicting Chinese early childhood classrooms that utilize military artefacts. Conflicting perspectives can surface taken-for-granted perspectives of proper artefact to facilitate belonging and thereby provide input regarding what to preserve, change or remove in taken-for-granted practices that aim to establish local, national and/or global belonging. 


\section{Contesting Artefacts in ECE}

Children's exposure to war toys has been contested in contrasting societal messages for young children related to the appropriateness of military toys [19]. Playfighting and use of war toys have been considered detrimental symbols of violence and aggression [20-22]. Hartmann and Borugere [17] find that war toys are controversial and unwanted for ethical and psychological reasons in many European countries. However, toys have been disseminating discourses of war for decades globally $[23,24]$. Today, children are exposed to war toys by the toy industry and the computer game industry. Machin and Van Leeuwen [23] (p. 52) state that "what is also important and not so well understood, is the way that the toys of different eras have prepared children for specific kinds of warfare, fought in particular ways fused with specific political ideologies about the meaning of war and the society itself during those times".

Exposure to war toys and artefacts in ECE institutions has also been contested. In Norway, for many years, the well-known toy company A/S Riktige Leker (Proper Toys) was an important stakeholder that recommended appropriate toys in Norwegian kindergartens [25]. The company had strong connections to the International Women's League for Peace and Freedom and to the Organisation Mondiale pour l'Education Prescholaire (OMEP). The company's pedagogical profile was peace work, humanitarian and social work. In 1949, the board sent a note to all toy wholesalers in Norway, asking them not to expose children to war toys, such as soldiers, tanks, guns and bombers. At an exhibition the same year, a headline asked rhetorically: Shall we raise children for war and destruction or build peace in children?" [25]. By excluding war toys, this company installed assumptions of appropriate pedagogical toys among generations of Norwegian kindergarten teachers. According to Korsvold [25], this note described children as vulnerable and victims of wars and as future agents for peace. After the Second World War, safety was an important value. Appropriate toys were part of this safety and war toys a marker of non-safety. In contemporary curricula for many ECE institutions in Norway, there is the same attitude toward military artefacts: "The staff do not want the children to bring war toys into the kindergarten" [26]. Although the skeptical approach to military artefacts is well established, it forms a contrast to artefacts present in Norwegian ECE institutions. Ødegaard's research [27] surfaces that commercial artefacts like captain Sablertooth's sword are often present in Norwegian ECE institutions. From our 30 years of involvements as ECE teachers and ECE teacher educators and researchers undertaking teaching, field work and guiding of students in ECE institutions, we know that bravery and nationalism can be traced to the presence of knifes in everyday life in kindergarten and the presence of the Royal Guard in the children's parade when celebrating our national day. To our knowledge, these contradictive approaches to artefacts that might represent possibilities both to harm and to protect are rarely investigated.

In contrast, in China, traditionally military artefacts have not been contested in the same way as in Norway [24,28]. Quite the contrary: "different regimes similarly deployed toys and play in order to foster children's engagement in struggles of a political, commercial or military nature" [24] (p. 17). Bai [29] investigated toys during the dynasties in China and found traces of current military artefacts in historical military activities, such as the use of kites and rope swings. These activities originated in serious contexts and then survived as simple amusements. However, they are not what today we consider war toys. Boretti [24] argues that "although mobilization was construed as defensive, patriotic activism and acquaintance with the metaphorical or real battlefield were significant components of Chinese children's upbringing from the beginning of the twentieth century". In addition, she outlines toys as indicating "a meeting of the worlds of children and adults" [24] (p. 17). Hung [30] describes how endless repetitions of Chinese political symbols became a natural part of installing patriotism in kindergarten children during the Cultural Revolution. With games, photographs, films and toys, the message of socialism and patriotism was mediated.

The issue of (non-) legitimation of military artefacts in ECE in China and Norway touches on contradictory values, such as fostering peace or avoiding wars or aggression, 
fostering patriotism, imparting knowledge about national history and even bonding adults and children during festivals that include an element of play.

\section{Artefacts, Cultural Formation, Belonging and Sustainability}

There is growing interest in materiality in ECE research and practice [31]. Despite ontological differences, it can be claimed that this research is continuing the legacy of Pestalozzi, Fröbel, Montessori, Dewey and Reggio Emilia that emphasizes the materials involved in specific activities [32]. In addition, Sutton-Smith's [15] iconic work addresses how toys play a significant role in the lives of children and their parents and how toys reflect values, demands, economy and stereotypes, as well as how we view children and play.

Several researchers who investigate what often is referred to as the "the material turn" lean on posthuman perspectives [8]. That is, they take an ontological standpoint from phenomenology, semiotics and discourse analytic approaches, while trying to challenge these approaches and the overall emphasis of humans and language as the center for meaning making. The objective of material turns is to challenge the humanistic approach that is taken for granted, in which language and ways of thinking are presented as the main ways to understand and learn, because the humanistic understanding of the subject leaves material-discursive elements, such as non-human materials (room, furniture, nature, toys, etc.) in the shadows $[33,34]$. Discursive formation due to these materials and hegemonic ideas about pedagogical practices, gender, age, ethnicity, social class and abilities, therefore, may be ignored [35,36].

We claim that the same might be the case when aiming at facilitating cultural sustainability and belonging in ECE: Hegemonic ideas about nationalism, peacebuilding, children and play may prevent us from insight into more sustainable living. Therefore, we take materials (military artefacts) as the object of study. In contrast to the material turn, where activities are the object of study, we aim to understand how graduate students and researchers' legitimation or non-legitimation of military artefacts can uncover constituted taken-for-granted approaches to cultural formation, belonging and social and cultural sustainability.

Building on Ødegaard and Krüger's [37] ideas of cultural formation, we understand it as an ever-present and continuous process. They describe cultural formation as a descriptive concept that portrays the acts of humans in relation to the conditions in their culture [34]. As these acts by humans are embedded in their culture, we understand cultural formation as fostering belonging in a culture. We investigate war toys and artefacts and the legitimation of their (non-)use, as one among several conditions that represent institutional and cultural values and demands. Therefore, we see artefacts as a part of the physical and social curricular space and as a condition for cultural formation [37]. Because culture is embedded in the curricular space reified by available artefacts and the themes emphasized in ECE, the notion of cultural sustainability and belonging comes up.

\section{Materials and Methods}

In order to forward normative complexity and conflicting perspectives within practices for cultural sustainability, we used polyvocal photo-elicitation. The use of photos during the interview process is a variation of open-ended interviewing [38,39], a non-directive interview that, although initiated and guided by the researcher, is intended to grant an interviewee greater space for personal interpretation and responses [40]. In photoelicitation, this exchange is stimulated and guided by images. Photos are open ended and by resisting single interpretations, photos can give rise to a range of alternative paths of inquiry $[39,41-43]$.

We included different stakeholders representing Chinese and Norwegian ECE researchers, kindergarten teacher educators and ECE graduate students. The aim of including different stakeholders was to explore and elaborate different interpretations of the images and possible conflicting perspectives. The discussions were not intended primarily as a path to the fusion of horizons [44] but as means of opening up the interview to opportunities for subjective and negotiated interpretations, descriptions and meanings [40]. 
Because the photographs have communicative properties, looking at the images during the interview constituted a joint interpretative event.

The interviews, were based upon six images (photos) of military artefacts in a Chinese classroom for 5-year-old children that we took when we visited the kindergarten. The first picture displayed a military obstacle course with two children in military uniforms crawling in a shooting position. The walls weredecorated with military symbols, colors and people in uniforms. The second and third pictures showed exhibitions of military weapons and vehicles from three military branches. The fourth picture showed a combination of exhibition and military artefacts made by children. The fifth picture showed a group of children dressed in military uniforms. In the sixth photo, two children were sitting in a military tank with their teacher cheering beside them.

In the interviews, we started to inform the participants about the aim of the research and the background of the exhibition of military artefacts in this specific kindergarten. Then, we showed the first photo and asked each participant one by one what they saw in the photo and what their reactions were to what they saw. Their comments were not discussed in this part of the focus group interview. After all the participants had commented and shared their interpretations of each of the six photos, they were asked the following questions: "What do you think the teacher want to achieve by this exhibition?", "What kind of values do you identify in this classroom?", "How would you legitimize use of military artefacts in kindergarten?", "How would you legitimize no use of military artefacts in kindergarten?" and finally "Is there anything you want to add?" These questions elicited perspectives from each participant, but also explanations and discussions with exchange of opinions and arguments among the participants.

\subsection{Empirical Material}

The empirical material was produced from two photo-elicited focus group interviews. The first interview included two graduate students from China and two from Norway. All the students were female. The students were selected based upon their cultural knowledge and experience with ECE in both countries. This interview was carried out with all the participants in the same physical room. The second interview included two ECE researchers from China and two from Norway. The four researchers were selected due to their cultural knowledge and experiences with ECE not only in their homeland, but also in the host country. In addition, experiences from both countries they all have been involved in research including ECE in both countries. As such, they were not completely outsiders to the ECE in any of the cultural contexts. Our preconception was that contextualized knowledge among the participants would enrich the reflections and arguments in the focus group interviews. All the researchers were female. This second interview was carried out digitally on Zoom. Each interview lasted for approximately two hours.

The focus group interviews were led by one of the authors. The interviews were not recorded, but one of the authors wrote down the comments during the interview. Both interviews were transcribed and sent to the participants for their comments on the transcription. Some participants used this opportunity to clarify the meaning of their statements and reflections.

\subsection{Analysis}

We performed a content analysis and organized the material into four categories, which reflected the main themes that arose during the interviews: conflicting perspectives about appropriate themes and artefacts in ECE, conflicting perspectives about childhood and children, conflicting perspectives on how to facilitate ways of belonging and conflicting perspectives on appropriate classroom decorations. In the presentation of the analysis and discussions, we discuss the first three themes and omit decorations as a theme. Although the legitimation or non-legitimation of military artefacts based on arguments regarding suitable decorations for young children's environments is interesting, the discussions centered on colors and art, rather than the presentation of military artefacts as such. 
In accordance with Grindheim's [45] outline of conflict analysis, we put conflicting perspectives about these themes in contrast to each other. In accordance with the question that structure this article, it is the conflicting perspectives and possible emerging insights into ways to facilitate cultural sustainability in ECE that is of interest.

\subsection{Ethical and Methodological Dilemmas}

The participants were informed about the purpose of the study when they gave informed consent. They were also informed that they could withdraw their consent anytime. One participant used the opportunity to withdraw. Therefore, we needed to organize a new focus group interview including a new participant. This incident made us even more aware of the sensitivity of the topic. We informed the new participants about the purpose of the study which is to provide insights into the cultural position of play material. By focusing on the use of military artefacts and toys, we want to challenge taken-for-granted arguments about the use of the military artefacts or toys as legitimate or not.

In this study, the photos were of a Chinese classroom in a specific time and at a specific occasion. The classroom was decorated and exhibited artefacts in connection to the celebration of the 70 years' anniversary of People's Republic of China. The National Day, October 1, is always a topic/theme in Chinese kindergartens. However, this year was special due to the anniversary. The choice of these specific photos for focus group interview was based upon our assumption that these photos could elicit conflicting perspectives on artefacts supporting belonging. The purpose was not to compare Chinese and Norwegian practices concerning belonging and cultural sustainability, but to provoke a diversity of arguments and possible conflicting perspectives. We could see that this led to a position of defense among some of the Chinese participants during the focus-group interviews. The Norwegian participants took a position more to understand the Chinese position and partly argue against what they saw. The Chinese participants had less opportunity to do so, as there were no corresponding photos from a Norwegian classroom. The situation illuminates how cross-cultural studies easily provoke defense and assessment of what is right and wrong, better or worse practices. The fact that we both are Norwegian researchers may have reinforced this tendency during the focus group interviews, although we repeatedly emphasized that the purpose was not to assess best practices.

\section{Results}

We present the conflicting perspectives by presenting utterances which represent the central arguments that came up several times or were made by several persons.

\subsection{Conflicting Perspectives about Appropriate Themes and Artefacts in ECE}

There are utterances supporting military artefacts in ECE. Some arguments pointed to the educational aims to learn about different weapons and military branches in China: "there are two ways that military artefacts are legitimized (1) To teach children about weapons and the development of them. (2), To tell the children how dangerous the advanced weapons are. Therefore, we have to be careful how we use the weapons". Another argument is that soldiers are good role models for children: "For children the soldiers and the military are ideals. Soldiers are strong, healthy, ambitious, brave, smart and thereby a guiding ideal for children". This ideal formed a contrast to informants' outline of the historical position of China: "It is a tradition to honor the military. Historically we have been weak and bullied. The military protect us and our country, we do not attack". The protection aspects of the military also have a civil aspect: "The military do not only protect us in wars; they save and protect us in crises like natural disasters, earthquake and fires". Arguments were also connected to social equity pointing to the fact that soldiers come from ordinary families: "Soldiers come from ordinary and even poor families from the villages and are trained to become national heroes". This point seems to be important to demonstrate for children in kindergartens. 
However, there were comments disputing military artefacts in ECE. An argument promoting peace was repeated several times: "What is early childhood education for. What is the purpose for early childhood education? What is important to us? Make peace or promote war?" Another participant was surprised by her own reactions to the exhibition of military artefacts: "I am fascinated by my own reactions: I see a boy organizing toys in a proper line, like with any kind of toys: cars, animals. However, when it comes to weapons and the military, it affects me. Weapons that make huge damages". Another argument was related to the question of play: "This do not look like play, but more like an information campaign about the military".

The conflicting perspectives derive from very different angles; from understanding these artefacts as promoting learning, promoting soldiers as strong, healthy, ambitious, brave, smart who can help in crises. These ideals for children form the opposite of the historically weak and bullied Chinese. In contrast, there were also interpretations of military artefacts as something glorifying wars and opposing the promotion of peace.

Due to our understanding of cultural sustainability and cultural formation, we suggest that the arguments supporting military artefacts emphasize the aim of education as learning about weapons and how to treat weapons because they are dangerous. Weapons, per se are dangerous; they are made to create danger. In this context, we interpret the argument as children need to learn to handle weapons to avoid harming themselves or persons in the community to which the children belong. Thus, we touch on cultural sustainability, as local or national belonging where people are safe. Other arguments for military artefacts are the educational ideal soldiers represent. The cultural formation aims at citizens who are strong, healthy, ambitious, brave, smart and able to protect and help in their community. To protect is closely connected to belong and be safe and the military is at the forefront as protection for those who belong against those who belong in other states. The arguments also support that the military provides opportunities for equity, because poor people can join the army and become heroes. In contrast, the contesting arguments for not including military artefacts in ECE are that play materials resembling dangerous weapons must be avoided. Weapons create damage, not peace. Military artefacts promote and symbolize aggression and war and might even transform children's play into a recruiting campaign for future soldiers. In these opposing arguments for not including military artefacts in ECE, belonging, being free from danger, protection and equity are not brought to the table.

\subsection{Conflicting Perspectives on Childhood and Children}

There were utterances supporting military artefacts as appropriate for children and in the childhood setting. Some informants even pointed to the familiarity of the topic, for example, by pointing to the national holiday in China, on October 1. "This is quite normal. All the Chinese kindergartens celebrate the national holiday on October 1". Another argument was about how children can be familiarized with their local surroundings: "Children in kindergartens should be exposed for the surroundings. They are exposed to schools, hospitals, fire-station, police-station, working places. Why should they be protected against the military?" A third argument was that this is not as much about the military: "It is a showoff" to demonstrate that you are doing what is expected, in a good way.

However, there were utterances disputing military artefacts as appropriate for children and in childhood settings, such as "this really violates my understanding of childhood. War and military uniforms belong to the adult world and we have to protect the children from the adult world. My associations go to children soldiers". Another argument pointed to the fact that war exists, but children need protection: "There is war all over the world. Countries protect themselves, but these are small children in kindergarten". These arguments saw military artefacts as symbols of war. One participant expressed this point as follows: "To me, as a kindergarten teacher I would have chosen peace and talk with children about how we create peace in the world. This is a political message that does not belong in kindergarten". 
The conflicting perspectives contest what is appropriate to expose children to. There were arguments for seeing the military as a natural part of the surroundings of children, that they should be exposed to all parts of social life and that ECE institutions should follow the curriculum. These arguments forward the need to mark and celebrate what is celebrated elsewhere in society, that the military is a part of their surroundings or neighborhood and thus, should be a part of their curriculum. The opposing arguments stated very clearly that children should be protected from this part of the adult world. It is too early to expose them to the military.

These conflicting perspectives are relevant for understanding which conditions are seen as appropriate for children in their physical and social curricular space. Based on our understanding of cultural sustainability and cultural formation, we interpret the utterances that support bringing knowledge about the military and military artefacts into the ECE institutions as representing an intergenerational approach to cultural formation and belonging. In contrast, the utterances that dispute bringing knowledge about the military and military artefacts into ECE institutions represent a view of childhood as a separate phase in the lifespan of humans. These opposing views ask for opposite approaches to children's cultural formation and their belonging.

\subsection{Conflicting Perspectives on How to Facilitate National Belonging}

There are utterances supporting the military as a theme for promoting belonging, pride and patriotism. One comment suggested that this is a clear expectation and a mandatory part of the Chinese curriculum plan: "National pride. It is one of the teacher's tasks; they are supposed to have these exhibitions. Kindergartens differs in ways to celebrate the national day". Another argument also connected the topic to the celebration of National Day: "I suppose they have had this as a kind of activity close to the national day. This day celebrates and show that we are proud of the army, it shows that we are strong, it promotes nationality and provide safety and how we are proud of our country. Kindergartens let the children do the parades that are performed at the national day, as dramatic play". The following comment suggested that the military museum is situated close by and thus, is an important cultural site to visit: "They have been undertaking the theme 'we are Chinese' around the national day. Here is a lot of things representing China's development. A lot of military things; do they have a military museum in this city? Perhaps they have visited there and wanted to make one".

However, there were comments disputing emphasizing the military as a theme for promoting belonging, such as "in Norwegian kindergartens, we don't see this kind of artefacts". "It is scary, unfamiliar to me". "I would not use them. They are war materials. I would never put children in military customs, like training them for war. For me and in Norway, connecting war and children are taboo. We will not make the children aware of wars". There is pointed to the Norwegian way of celebrating National Day: "We celebrate the 17th of May, as a children's day. There are no military artefacts at all". "The Norwegian celebration includes parades with children, followed by eating ice cream and playing games facilitated and joined by adults, quite different from the military parade on October 1 , in China".

The conflicting perspectives reveal that those who dispute the emphasis of the military as a theme in ECE look at military artefacts as war artefacts and as a way to promote war and fighting, rather than as ways of celebrating National Day and promoting national belonging. Chinese children are exposed to the military parade on the holiday. They watch it on TV and in this way, are familiarized with it. Norwegian children have no such experiences. The military is "hidden" from civilian life and the national holiday is celebrated with a children's parade for kindergarten and school children and no military parade. The analysis of this material surfaced that exposure to military artefacts is not an expected way to promote cultural and national belonging in Norway. Based on our understanding of cultural sustainability and cultural formation, belonging, national pride and cultural formation are facilitated in contradictory ways. 


\section{Discussion and Further Challenges}

The analysis materialized that available artefacts in Chinese ECE represent historically established educational ideals, such as patriotism and educational practices offering military artefacts. We trace established Chinese traditions for bringing military artefacts into play as described by Boretti [24]. We also suggest that the elements of "showing off" and play in Chinese military parades [26] are mirrored in the interview material and are close to an intergenerational approach to play, children and childhood. We also found that war toys or military artefacts are unwanted among Norwegian participants who referred to the danger of inducing aggression and violence, as pointed out by Hartmann and Borugere [17] and Korsvold [25]. The historical Chinese approach to military artefacts described by Boretti [24] that is also surfaced in the present material provides insight into knowledge and consciousness regarding the educational possibilities embedded in the chosen artefacts enrolled in play and makes it evident that the material parts in educational practices, such as artefacts, should not be ignored

The conflicting perspectives that emerge from our analysis, made us as Norwegian researchers realizing that the taken for granted approach embedded in a skeptical approach to military artefacts can be seen differently. First, we realized that we and the Norwegian participants in the interviews, called these artefacts war-toys, making a direct line from the artefacts to something that represent wars. The analysis surface that this is not the sole relevant line when seeing them in the perspective of belonging and protection. Second, the conflicting perspectives made awareness of national belonging and patriotism, that probably is present in any nation. Despite the relevance of patriotism when discussion celebration of national days, this aspect is not touched upon by the Norwegian participant. This may indicate that the Norwegian national pride is embedded, taken for granted and seldom confronted. Aware of the patriotic aspect, it became relevant to consider that patriotism can be facilitated in several ways. Can the acceptation of young children using knifes in Norwegian ECE institutions be traced to Norwegian patriotism towards individual capacities to survive by both making hunting equipment and protecting materials? Knowledge of how to use knifes makes us survive in nature, like good Norwegians are supposed to and might form a distinction to people from other nations. Third, the notion of childhood as a separate life phase is challenged, the conflicting perspectives depict how entanglement between generations are present, anyway.

In this article, we aim at providing more insight into social and cultural sustainability, understood in the ECE context as creating surroundings (i.e., artefacts) that include and stimulate positive interactions, such as promoting a sense of community and a feeling of belonging to the community in which we live by being safe and attached to the local area. Although both the Chinese Guidelines and the Norwegian Framework plan forward belonging to the local area, the analysis showed how cultural formation and where to belong are intertwined. The conflicting perspectives are mostly related to the national level; to military artefacts as conditions to forward unity and belonging in a nation. Despite of the limitations of our material for analysis, the analysis surface how the historical and demographical context is intertwined in what is highlighted as relevant for belonging. In a homogenous country with a small population-like Norway, the love of the country can be taken for granted. In a heterogenic nation with an enormous population-like China, it makes sense that education forward national unity. From the analysis, we suggest that cultural formation potential from involving military artefacts in ECE practices can constitute belonging, depending on where belonging is meant to be situated. This reveal that further investigations about artefacts as conditions for social and cultural belonging in a variety of nations, is of major interest.

Our analysis also indicates how belonging, being safe and being protected are closely connected. Being protected and being safe do not necessarily represent values of belonging and positive interactions, in a wider context. Belonging is often facilitated by building borders against those who do not belong or belong elsewhere. From an international perspective, that does not represent safety. Therefore, the presented contradictions and 
contradictive approaches to military artefacts raise questions not only about how to facilitate belonging but also where to facilitate belonging. Local belonging is most relevant for children. This serves as an argument for approaching local and national themes that unite, such as the military, for young people and form a contrast to the argument that children are too young for such issues.

These conflicting perspectives on belonging locally, nationally or internationally demonstrate a paradox within social and cultural sustainability. As human beings, we need local belonging, but if protecting local belonging causes wars that are damaging for humans, nature and cultures, we do not develop sustainability. To get around the paradox, we might ask whether the notion of belonging must be something that excludes others who belong in other nations. We ask whether belonging locally or internationally can be facilitated without references to national borders. Can belonging be facilitated without viewing those who belong elsewhere as a threat?

Author Contributions: Both researchers contributed equally and Both authors have read and agreed to the published version of the manuscript.

Funding: This research was funded by The Norwegian Research Council (NFR) and Directorate of Quality in Education (DIKU).

Institutional Review Board Statement: Ethical review and approval were waived for this study, due to the rules of approval from NSD, The Norwegian centre for research data. The research has followed NSD's rules for ethics.

Informed Consent Statement: Informed consent was obtained from all subjects involved in the study.

Data Availability Statement: The data presented in this study are available on request from the corresponding author. The data are not publicly available due to ethical restrictions of identification.

Acknowledgments: We acknowledge the KINDknow research center that have supported the work. We want to thank the kindergarten who let us take photos. We also want to thank the researchers and graduate students who participated in the study.

Conflicts of Interest: The authors declare no conflict of interest. The funders had no role in the design of the study; in the collection, analyses, or interpretation of data; in the writing of the manuscript, or in the decision to publish the results.

\section{References}

1. United Nations. Transforming Our World: The 2030 Agenda for Sustainable Development. Available online: http://bit.ly/ TransformAgendaSDG-pdf (accessed on 1 October 2020).

2. United Nations Educational, Scientific and Cultural Organization. Towards a Sustainable Future. Available online: http: //www.unesco.org/education/tlsf/mods/theme_gs/mod0a.html (accessed on 1 October 2020).

3. UN's Sustainable Development Goal 4. Available online: https://sustainabledevelopment.un.org/sdg4 (accessed on 1 October 2020).

4. Samuelsson, I.P. Why we should begin early with ESD: The role of early childhood education. Int. J. Early Child. Educ. 2011, 43, 103-118. [CrossRef]

5. Davis, J. Examining early childhood education through the lens of education for sustainability: Revisioning rights. In Research in Early Childhood Education for Sustainability: International Perspectives and Provocations; Davis, J., Elliott, S., Eds.; Routledge: London, UK, 2014; pp. 21-37.

6. Phillips, L.G. I want to do real things. Exploration of children's active community participation. In Research in Early Childhood Education for Sustainability: International Perspectives and Provocations; Davis, J., Elliot, S., Eds.; Routledge: London, UK, 2014; pp. 194-207.

7. Grindheim, L.T.; Bakken, Y.; Hauge, K.H.; Heggen, M.P. Early childhood education for sustainability through contradicting and overlapping dimensions. ECNU Rev. Educ. 2019, 2, 374-395. [CrossRef]

8. Grindheim, L.T. Approaching agency in intra-activities. In Childhood Cultures in Transformation. 30 Years of the UN Convention of the Right of the Child in Action towards Sustainability; Borgen, J.S., Ødegaard, E.E., Eds.; Brill NV: Leiden, The Netherlands, 2020; pp. 214-228.

9. Boldermo, S.; Ødegaard, E.E. What about the migrant children? The state-of-the-art in research claiming social sustainability. Sustainability 2019, 11, 459. [CrossRef]

10. McKenzie, S. Social Sustainability: Towards Some Definitions. Hawke Research Institute Working Paper Series. 2004, Volume 27, pp. 1-29. Available online: https:/ / www.unisa.edu.au/siteassets/episerver-6-files/documents/eass/hri/working-papers/ wp27.pdf (accessed on 18 November 2020). 
11. Mannion, G.; Adey, C. Place-based education is an intergenerational practice. Child. Youth Environ. 2011, 21, 35-58.

12. Heggen, M.P.; Sageidet, B.M.; Goga, N.; Grindheim, L.T.; Bergan, V.; Krempig, I.W.; Lynngård, A.M. Children as eco-citizens? NorDiNA 2019, 4, 387-402. [CrossRef]

13. MOE (Ministry of Education, China). Early Learning and Development Guideline Age 3-6; Ministry of Education: Beijing, China, 2012.

14. Norwegian Directorate for Education and Training. Framework Plan for Kindergartens-Contents and Tasks. Retrieved from Framework Plan for Kindergartens. Available online: https: / /www.udir.no/ (accessed on 15 October 2020).

15. Sutton-Smith, B. Toys as Culture; Gardener Press: London, UK, 1989.

16. Wartofsky, M. Models: Representation and Scientific Understanding; Reidel: Dordrecht, The Netherlands, 1979.

17. Hartmann, W.; Brougère, G. Toy culture in preschool education and children's toy preferences. In Toys Games Media; Erlbaum: Mahvah, NJ, USA, 2004; pp. 37-54.

18. Sutton-Smith, B. War toys and childhood aggression. Play Cult. 1988, 1, 57-69.

19. Hart, J.; Tannock, M. Play: Playfighting and war toys I Encyclopedia on Early Childhood Development. Young Children's Play Fighting and Use of War Toys: Encyclopedia on Early Childhood Education. 2013. Available online: http://www.child-encyclopedia. $\mathrm{com} /$ (accessed on 15 October 2020).

20. Hellendoorn, J.; Havinck, F.J.H. War toys play and aggression in Dutch kindergarten children. Soc. Dev. 1997, 3, 340-354. [CrossRef]

21. Watson, M.W.; Peng, Y. The relation between toy gun play and children's aggressive behavior. Early Educ. Dev. 1992, 3, 370-389. [CrossRef]

22. Holland, P. Take the toys from the boys? An examination of the genesis of policy and the appropriateness of adult perspectives in the area of war, weapon and superhero play. Citizsh. Soc. Econ. Educ. 2000, 4, 92-108. [CrossRef]

23. Machin, D.; Van Leeuwen, T. Toys as discourse: Children's war toys and the war on terror. Crit. Discourse Stud. 2009, 6, 51-63. [CrossRef]

24. Boretti, V. Patriotic fun: Toys and mobilization in China from the Republican to the Communist era. In War and Childhood in the Era of the Two World Wars; Honeck, M., Marten, J., Eds.; Cambridge University Press: Cambridge, UK, 2019; pp. 17-34.

25. Korsvold, T. Proper toys for proper children: A case study of the Norwegian company A/S Riktige Leker (Proper Toys). In Childhood and Consumer Culture. Studies in Childhood and Youth; Buckingham, D., Tingstad, V., Eds.; Palgrave Macmillan: London, UK, 2010; pp. 31-45.

26. Annual Plan for Kindergarten. Årsplan del 1-Generell del. September 2016. Available online: https:/ /www.oksnes.kommune.no/ tjenester/skole-og-barnehage/barnehage/barnehager/strengelvag-barnehage/arsplan-2020-2021/ (accessed on 12 October 2020).

27. Ødegaard, E.E. Piracy in policy: Children influencing early childhood curriculum in Norway. In Debates on Early Childhood Policies and Practices. Global Snapshots of Pedagogical Thinking and Encounters; Papatheodorou, T., Ed.; Routledge: New York, NY, USA, 2012; pp. 27-37.

28. Naftali, O. Marketing war and the military to children and youth in China: Little red soldiers in the digital age. China Inf. 2014, 28, 3-25. [CrossRef]

29. Bai, L. Children at play. A childhood beyond the Confucian shadow. Childhood 2005, 12, 9-32. [CrossRef]

30. Hung, C.-T. Turning a Chinese kid red: Kindergartens in the early People's Republic. J. Contemp. China 2014, 23, 841-863. [CrossRef]

31. Prout, A. Taking a step away from modernity: Reconsidering the new sociology of childhood. Glob. Stud. Child. 2011, 1, 4-14. [CrossRef]

32. Ødegaard, E.E. Meiningsskaping i bruk av artefakter. In Barnehagen som Danningsarena; Ødegaard, E.E., Ed.; Fagbokforlaget: Bergen, Norway, 2012; pp. 91-112.

33. Hultman, K.; Lenz Taguchi, H. Challenging anthropocentric analysis of visual data: A relational materialist methodological approach to educational research. Int. J. Qual. Stud. Educ. 2010, 23, 525-542. [CrossRef]

34. Sandvik, N. Posthumanistiske perspektiver. Bidrag til barnehageforskning. In Metodefestival og ØyeblikksrealismeEksperimenterende Kvalitative Forskningspassasjer; Ottestad, A.M., Reinertsen, A.B., Eds.; Fagbokforlaget: Bergen, Norway, 2015; pp. 45-62.

35. Barad, K. Posthumanist performativity: Toward an understanding of how matter comes to matter. Signs J. Women Cult. Soc. 2003, 28, 801-831. [CrossRef]

36. Latour, B. Reassembling the Social: An Introduction to Actor-Network-Theory; Oxford University Press: London, UK, 2005.

37. Ødegaard, E.E.; Krüger, T. Studier av barnehagen som danningsarena. In Barnehagen som Danningsarena; Ødegaard, E.E., Ed.; Fagbokforlaget: Bergen, Norway, 2012; pp. 19-47.

38. Tobin, J.J.; Wu, D.Y.H.; Davidson, D.H. Preschool in Three Cultures. Japan, China, and the United States; Yale University Press: New Haven, CT, USA, 1989.

39. Tobin, J.J.; Hsueh, Y.; Karasawa, M. Preschool in Three Cultures Revisited: China, Japan and the United States; University of Chicago Press: Chicago, IL, USA, 2009. [CrossRef]

40. Lapenta, F. Some theoretical and methodological views on photo-elicitation. In The SAGE Handbook of Visual Research Methods; Margolis, E., Pauwels, L., Eds.; Sage: Los Angeles, CA, USA, 2011; pp. 201-212.

41. Liu, C.; Tobin, J.J. Group exercise in Chinese preschools in an era of child-centered pedagogy. Comp. Educ Rev. 2019, 62, 5-30. [CrossRef] 
42. Birkeland, Å. Research dilemmas associated with photo elicitation in comparative early childhood education research. Res. Comp . Int. Educ. 2013, 8, 455-467. [CrossRef]

43. Birkeland, $\AA$. Contradictory Cultural Formation Ideals in a Time of Increased Emphasis on Individualization. A Cross-Cultural Study of Kindergarten Practices in China and Norway. Ph.D. Thesis, Norwegian University of Science and Technology, Trondheim, Norway, 2020.

44. Gadamer, H.-G. Truth and Method; Continuum: London, UK, 2004.

45. Grindheim, L.T. Conflict analysis: A methodology for exploring children's cultural formation in early childhood education. In Children's Exploration and Cultural Formation; Hedegaard, M., Ødegaard, E.E., Eds.; Springer Open: Cham, Switzerland, 2020; pp. 65-81. 